\title{
Determinants of Maternal Health Care Utilization in the Era of Free Maternity Services in Busia County, Kenya
}

\author{
B. Wafula, J. Arudo, M. Kipmerewo
}

\begin{abstract}
Purpose. The main objective was to establish determinants of maternal health care utilization and specifically to assess the trends of maternal health care utilization and determine the predictors of maternal health care service utilization in the era of free maternity policy in Busia County.
\end{abstract}

Methodology. It was a cross-sectional study design. The study was conducted between February and April 2019. The research targeted mothers within childbearing age of 15-49 years and a sample size of 634 mothers was used. Quantitative data were analyzed using SPSS version 22.0. Descriptive statistics was used to describe results on socio-demographic characteristics while inferential statistics employed bivariate and multivariate logistic regressions to investigate determinants of maternal health care utilization. Odds ratio was used to test the strength of association, and a p-value of $\leq$ 0.05 considered as statistically significant.

Results. In 2010, FANC increased by $5.6 \%$ from 2010 (prefree maternity period) to 2017 (post-free maternity era). There was also an increase of $2.2 \%$ cases of health facility deliveries during pre-free maternity period (2010) and post-free maternity period (2017). Eleven predictors of maternal health care utilization were identified. Among them were respondent being a farmer $(O R=2.6 ; 95 \%$ CI: $1.4-4.8 ; p=0.002)$, the status of the infrastructure of the nearest health facility maternity being $\operatorname{good}(\mathrm{OR}=3.2 ; 95 \%$ CI: $1.1-9.6 ; p=0.03)$, fare for the public vehicle being USD $0.2(\mathrm{OR}=3.4 ; 95 \% \mathrm{CI}$ : 1.6-7.1; $p=0.001)$, all maternal health services being available in the nearest health facility $(O R=3.1 ; 95 \%$ CI: 1.8-5.4; $\mathbf{p}<0.0001$ ), difficulty to attend MCH services due to nonsuitability of working days $(O R=2.7 ; 95 \%$ CI: 1.5-4.7; $\mathrm{p}=\mathbf{0 . 0 0 0 8})$, there being some services that clients pay for $(\mathrm{OR}=$ 3.3; 95\% CI: 1.5-7.4; $p=0.004)$, services being provided by nurses (midwives) $(\mathrm{OR}=2.3 ; 95 \% \mathrm{CI}: 1.0-4.9 ; \mathrm{p}=0.04)$, baby checkup being done within 24 hours by nurses (OR = 18.8; 95\% CI: 8.0-44.0; $\mathbf{p}<0.0001$. In conclusion, free maternity care program has led to increased utilization of facility ANC visits and deliveries in the study area. Barriers related to utilization of maternal health care services included unreliable transport especially at night, limited infrastructure and low socioeconomic status of the women in the study area. National and county governments need to put in place strategies which will help them to jointly assess, map and plan investments to improve utilization of maternal health care services through prioritizing investments in human resource, infrastructure and commodities based on the anticipated demand for such services.

A unique contribution to theory, practice, and policy: The study findings identified key factors that are unique to the mothers in Busia County on predisposing factors, enabling factors and the need characteristics that determine utilization

Published on August 31, 2020.

B. Wafula, Masinde Muliro University of Science and Technology, Kenya. (corresponding e-mail: wafulakhisa25@gmail.com)

J. Arudo, Masinde Muliro University of Science and Technology, Kenya.

M. Kipmerewo, Masinde Muliro University of Science and Technology, Kenya. of maternal health care in the era of Free Maternity services in the study area. These results contribute to both maternal health care utilization and policy change that could directly meet the social setting, geographical location and cultural needs of the people of Busia County.

Index Terms - Determinants, maternal health care utilization, free maternity policy, Busia County.

\section{INTRODUCTION}

Globally, approximately 830 women die daily from avoidable causes that are associated with childbirth and pregnancy. Out of all the reported maternal deaths worldwide, $99 \%$ are experienced in low-income countries. The maternal mortality rate of women mostly residing in rural areas and those from poor communities is relatively high. For every mother who dies, approximately twenty other women are exposed to serious injuries, health problems or disabilities [1].

The chances of a woman dying during pregnancy or childbirth in low-income countries are 1 in 39 compared to 1 in 3,800 in high-income countries [2]. Ensuring that all mothers deliver their babies with the aid of skilled birth attendants and easy accessibility of emergency obstetric care has been proven as the most important way of reducing maternal and newborns deaths [3]. Many factors have been identified as predictors of utilization of maternal health care services by women which includes cost of care. This has led to the introduction of different approaches both globally and specifically in the African region. Their main objective is to cut down the monetary barriers to health care with priorities being emphasized on vulnerable groups and high priority services. This intention is aimed at accelerating the maternal health care utilization which in turn reduces the maternal mortality rate [4].

Maternal mortality rate in Kenya is at 362 deaths in every 100,000 live births. This is well above the SDG 3 which has set a target of 70 per 100,000 live births by the year 2030 [5]. Conditions during perinatal period causes $9 \%$ of deaths in the country and thus maternal mortality is a leading health issue in Kenya [6].

In 2013, free maternity care (FMC) program was introduced by the government of Kenya after reports revealed that over 6000 women were dying annually from causes that can be prevented during pregnancy and childbirth. This program waivered financial barriers that are related to the usage of maternal health services and were designed to ensure all Kenyan mothers have access to maternity services in public facilities. This was expected to improve skilled health delivery from $44 \%$ recorded by the Ministry of Health in 2008 and improve the attendance and 
quality of postnatal care [7], [8].

Busia County fourth quarter Maternal Perinatal Death Surveillance and Response (MPDSR) review meeting of 2018/2019 reported 59.9\% ANC attendance meeting FANC requirement, $58.5 \%$ skilled birth deliveries, and maternal mortality rate of 307 deaths per 100,000 deliveries. The poor statistics were attributed to underutilization of maternal health care services in spite of the county having implemented free maternity program in line with the national government requirements. Thus, the expected reduction of maternal mortality ratio to less than 70 per 100 000 live births and meeting SDG 3 target by 2030 appears to be a mirage unless factors contributing to the underutilization of the maternal care services are investigated. Thus, this study sought to assess determinants of maternal health care utilization in the era of free maternity services in Busia County to help in achieving the Sustainable Development Goal 3 on maternal health by the year 2030.

\section{STATEMENT OF THE PROBLEM}

According to Save The Children report [9], Kenya is among the countries that ranked lowest to give birth in. National maternal rate is 362 for every 100,000 live births which although lower than the original 488/100,000 still account for $14 \%$ of deaths among mothers aged 15 and 49 years old. Despite the interventions and efforts that the state has put in place that is aimed at reducing the maternal mortality, e.g. the National Reproductive Health Policy Framework in 2007, doing away with user fees in all primary health facilities, national expanded free maternity services system also known as 'Linda Mama', Beyond Zero campaign promoted by the First Lady, only 58\% of mothers meet the minimum four ANC visits while $62 \%$ of women give birth under skilled attendance with $51 \%$ of women attending a postnatal checkup within two days after delivery. This is far below the $90 \%$ target by the year 2030 [10], [11]. Busia County continue to record low skilled birth deliveries (58.5\%) ANC attendance meeting focused antenatal clinic (FANC) requirement $(59.9 \%)$ and high maternal mortality rate (307 deaths per 100,000 live births). No study has been conducted in the county to examine determinants of utilization of maternal health care services and hence, vital information that would guide focused policy that would improve maternal health care is lacking. Thus, this study sought to assess determinants of maternal health care utilization in the era of free maternity services in Busia County.

\section{OBJECTIVES}

\section{A. Main objective}

The main objective was to assess determinants of maternal health care utilization.

\section{B. Specific objectives}

1. To assess the trends of maternal health care utilization during pre- and post FMC period.

2. To determine the predictors of maternal health care service utilization in the era of free maternity policy in Busia County.

\section{Methodology}

Study Design: The study adopted cross-sectional study design.

Study Setting: The study was carried out in Teso North Sub-County in Busia County, Kenya. The sub-county has a population of 139,524 persons which translates into a population density of 399 persons $/ \mathrm{km} 2$. It is among the 31 sub-counties that make up the former Western Province and is bordered by Bumula to the East, Teso South to the South, Bungoma West to the North East, Cheptais Sub County to the North, and Uganda to the West. The sub-county is divided into two divisions namely Amagoro and Angurai. These are further divided into 17 locations and 44 sublocations [12].

Study Population: The target population were mothers aged 15-49 years.

Sampling Technique: Multi-stage cluster sampling was applied in this research. Six locations out of the seventeen from the two divisions in the sub-county were selected through simple random sampling (SRS) method. In every location selected, a sub-location was randomly chosen and five villages in every selected sub-location using SRS approach. A total of 634 households from the list of all households in sampled villages were randomly picked using sampling frame prepared with the assistance of village elders and community health volunteers. At the household level, respondents meeting the inclusion criteria were selected.

The questionnaire and data extraction tool used to collect the required information on utilization of maternal health care services. We adopted and modified questionnaires used by Atasige et al. [13] and Ameh et al. [14] which were used to collect information from respondents on predictors of maternal health care utilization. Secondary data used to assess trends in maternal health care utilization for pre- and post-free maternity programme periods were extracted using a data extraction tool.

Inclusion Criteria: All women within the reproductive age (WRA) of 15-49 years and residents of the study area and having been residents for at least six months preceding the commencement of the study were invited to participate in the study.

Exclusion Criteria: Women who were mentally challenged, terminally ill or non-residents were excluded from the study.

Sample Size Determination: The sample size determination was done using Fisher's method [15]. The final sample size was 634 respondents which took into account $10 \%$ loading population which took care of possible refusals.

Research Instruments: The researcher modified and adopted a questionnaire used by Atasige [13] and Ameh [14] that were applied in a cross-sectional survey study in a rural northern Ghana-Gushegu District and Cross River State in Nigeria, respectively. Utilization (users) of maternal health care services was operationalized as women who attended ANC at least four times during the previous pregnancy, delivered by skilled birth attendants and went for the postnatal check-up within the recommended two days.

Quantitative data collection tool: The researcher used a structured interviewer-administered questionnaire divided 
into 2 sections. Section 1: Demographic and socio-economic characteristics and Section 2: Predictors for maternal health care utilization. The questionnaire was in English language and translated into Kiswahili and back translated into English to identify discrepancies between these two versions that could be due to errors in the actual translation. Secondary data on trends of maternal health care utilization for pre- and post-policy periods was extracted using a data extraction tool designed by the researcher.

Data collection procedure: The Researcher conducted a three-day orientation training for 3 research assistants who collected data from the participants using a structured questionnaire. The research assistants were familiar with the study site and were assisted by community health volunteers to identify the sampled households. For households with more than one eligible respondent, ballot paper was used to select the respondent who was interviewed.

Data analysis: Quantitative data were entered, cleaned, coded, and analyzed using SPSS software (Statistical Package for Social Sciences) version 22. Descriptive statistics was used to describe results on socio-demographic characteristics while inferential statistics employed bivariate and multivariate logistic regressions to investigate determinants of maternal health care utilization. Odds ratio was used to test the strength of association, and a p-value of $\leq 0.05$ considered as statistically significant.

\section{FINDINGS AND DISCUSSION}

A. Findings

1. Trends in antenatal visits during pre-and post-free maternity period

Results in Fig. 1 presents distribution of ANC visits during the pre- and post-free maternity period, 2010 to 2013 , and 2014 to 2017, respectively. There was very little variation in terms of the proportion of ANC visits in both periods for the three categories of ANC visits reported. A progressive increasing trend in both periods in the three categories reported was observed. The number of 1 st ANC visit increased from $10.8 \%$ in 2010 to $12.2 \%$ in 2013 in the pre-free maternity period while in the post-free maternity period, it increased from $13.5 \%$ in 2014 to $14.1 \%$ in 2016 with a slight drop in 2017 (12.9\%). A similar trend was noted in mothers' meeting FANC requirements of at least 4 ANC visits. In 2010 they increased from $9.8 \%$ to $10.2 \%$ in 2013 in the pre-free maternity period while in the post-free maternity it increased from $13.3 \%$ in 2014 to $15.4 \%$ in 2017. There was a discernable increasing trend in the period covered.

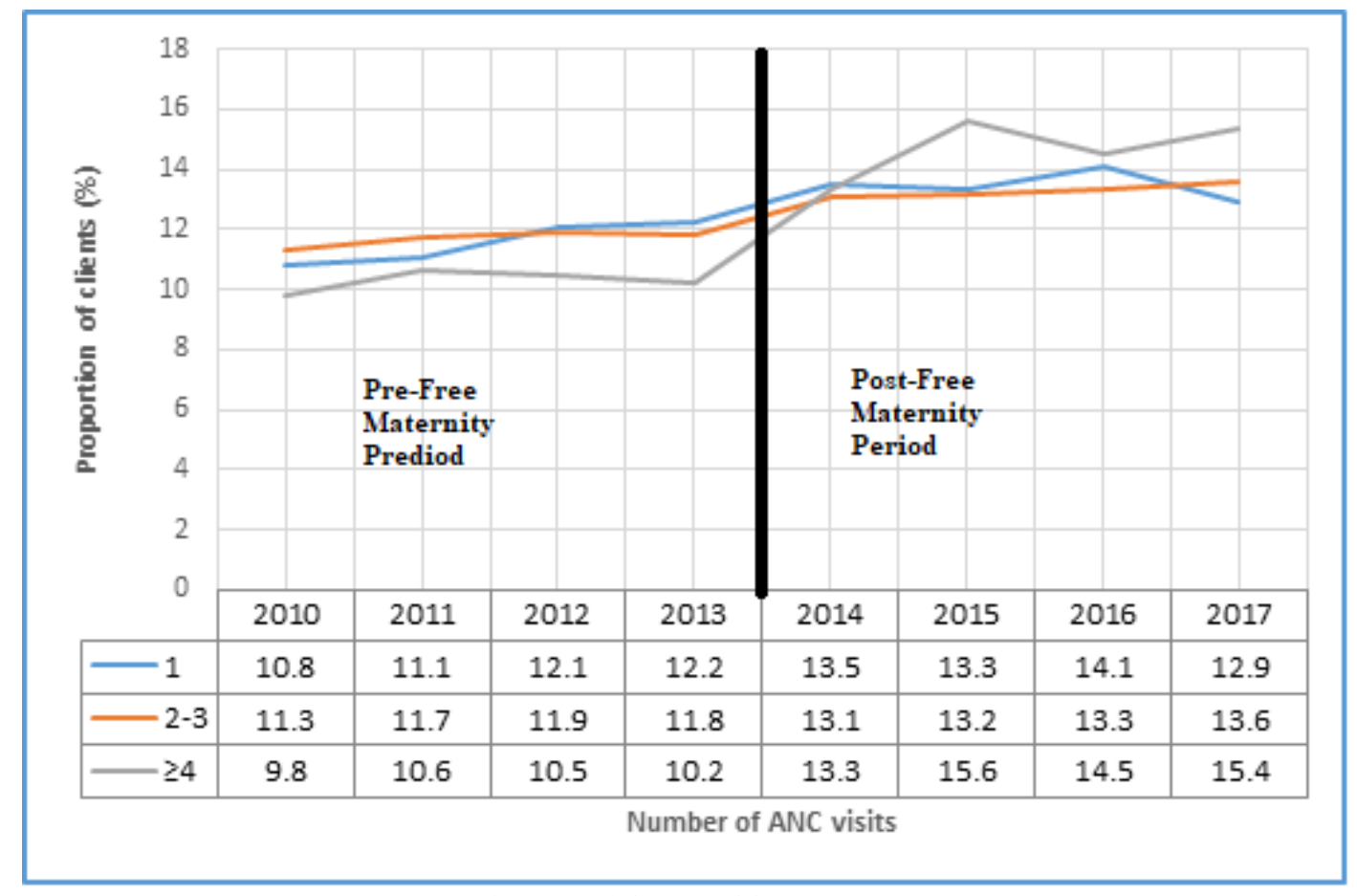

Fig. 1. Trends in ANC visits (2010-2017).

2. Trends in mode of health facility deliveries during pre- and post-free maternity period

Figure 2 illustrates the distribution of mode of deliveries in the pre- and post-free maternity periods. Again, there was little difference in the proportion of mothers who delivered through the four modes of deliveries. As expected, deliveries through SVD was the most common with over $90 \%$ of the mothers falling in this category. There was an increasing trend with respect to proportion of women who delivered through SVD before and after the implementation of free maternity policy with noted increase from $10.2 \%$ in 2010 to $15.1 \%$ in 2017. 


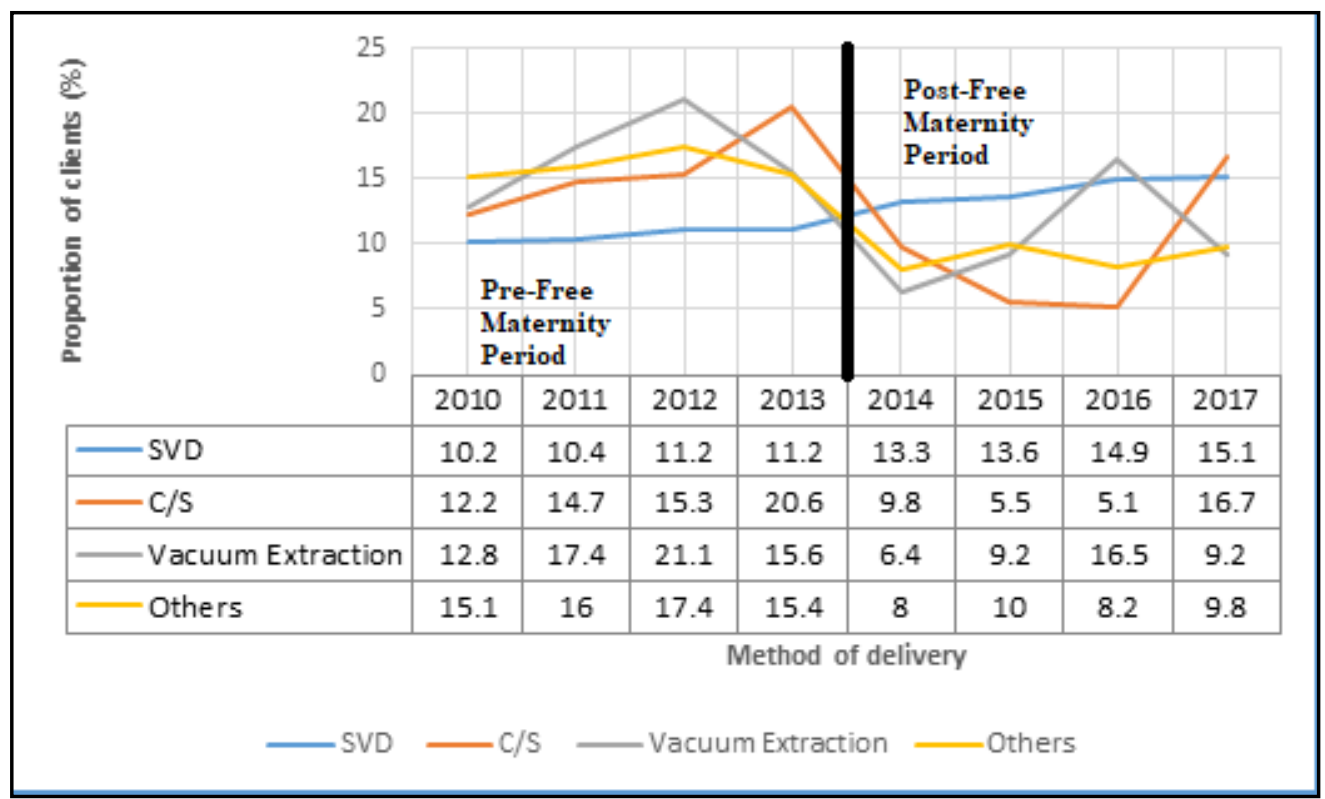

Fig. 2. Trends in methods of delivery (2010-2017).

3. Timing of postnatal check-up during pre-and postfree maternity period

Figure 3 shows trends in the timing of postnatal checkups for mothers who delivered between 2015 and 2017. As observed in both ANC and delivery, the proportion of mothers attending postnatal checkups showed a progressive increase trend in all categories observed except in 2017 where we had a small drop in mothers attending after the fourth week. Mothers attending postnatal checkup within 2 days increased from $7.9 \%$ in 2015 to $48 \%$ in 2017 . In 2017, there was a drop to $33.8 \%$ and $36.2 \%$, respectively of mothers attending postnatal checkups after 4 to 6 and more than 6 weeks. Postnatal care is recommended for both the child and the mother since it helps in preventing complications that may arise during childbirth. During the check-up, parents are also provided with basic information necessary for the upbringing of the baby and self-care. All women are recommended to obtain a postnatal checkup within two days of delivery [5].

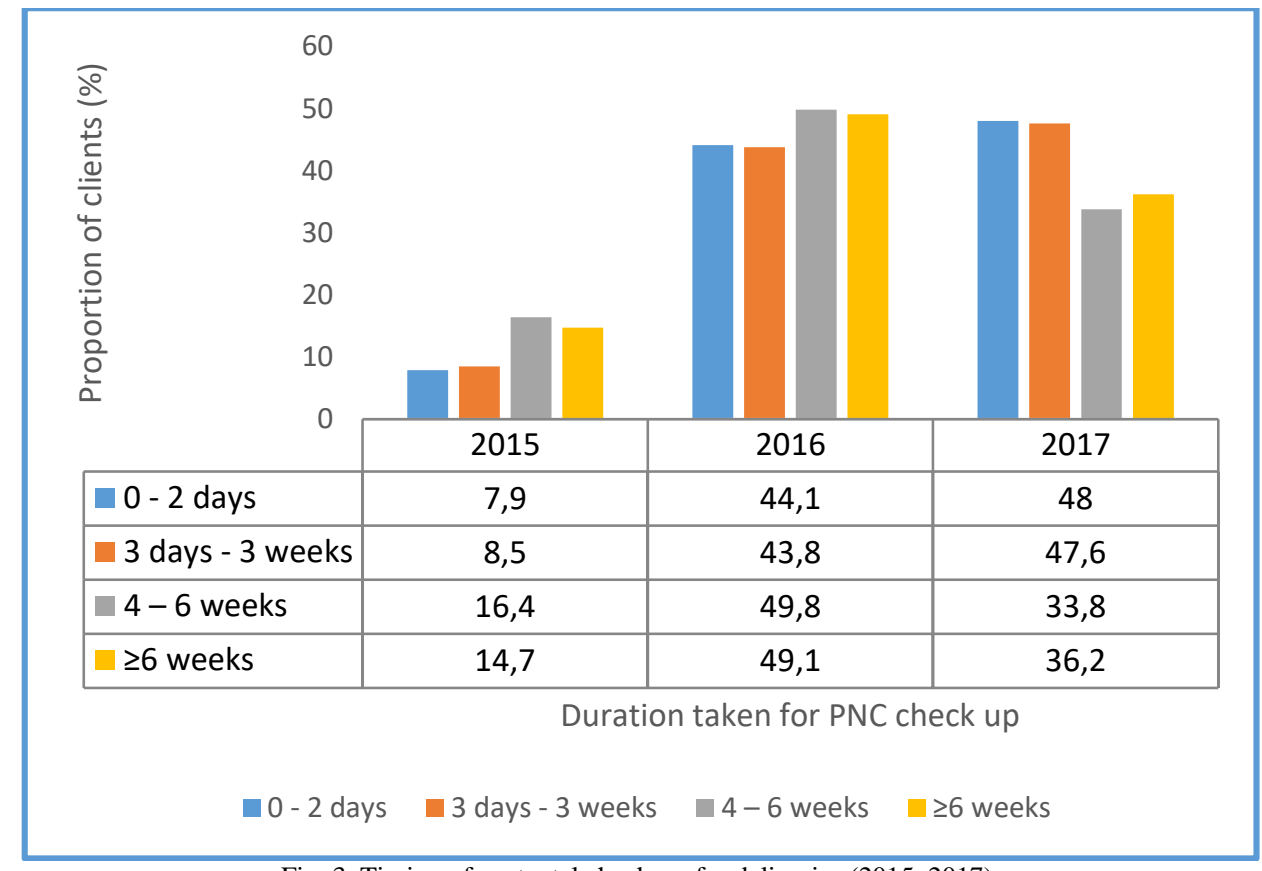

Fig. 3. Timing of postnatal check-up for deliveries (2015-2017).

4. Socio-demographic characteristics of respondents

A total of 608 survey questionnaires were administered in the study site. Out of this total $554(91.1 \%)$ were complete and the data entered and analyzed. The incompleteness of entries was the main reason for having rejected $8.9 \%$ $(n=54)$. The proportion of complete entries is considered adequate for generalization of study findings in areas with similar settings.

Table 1 shows compares socio-demographic characteristics of mothers who were users and non-users of maternal health care services in the study area. Out of 554 respondents, 202 met the criteria of users giving a prevalence of $36.5 \%(n=202)$. Most users $(41.6 \%)$ and nonusers $(34.7 \%)$ were aged 25 to 29 years of age. The mean age was 27.4 years for users with a range of 18 to 38 years 
while that of non-users was 27.5 and ranged from 18 to 39 . The difference in mean age was statistically not significant $(\mathrm{t}=0.3$; df: 552; $\mathrm{p}=0.7)$. Among users and non-users, the difference in level of education was statistically significant $(\mathrm{p}=0.01)$ with respect to primary level education with a higher proportion of users $(51.5 \%)$. A relatively higher proportion of users were farmers $(63.5 \%)$ in contrast to non- users (74.1\%) with the difference being statistically significant $(\mathrm{p}=0.008)$. Notable difference was also reported among users $(60.2 \%)$ and non-users $(62.3 \%)$ with respect to husbands who were farmers $(\mathrm{p}<0.0001)$ and average monthly income $(\mathrm{p}<0.0001)$ for users $(58.6 \%)$ and nonusers $(58.7 \%$ ) earning less than KSh. 10,000 (USD 100).

TABLE 1: DEMOGRAPHIC AND SOCIOECONOMIC CHARACTERISTICS OF THE RESPONDENTS

\begin{tabular}{|c|c|c|c|c|c|c|c|}
\hline \multirow{3}{*}{ Variables } & \multirow{3}{*}{ Categories } & \multicolumn{4}{|c|}{ Utilization } & \multirow{2}{*}{$\begin{array}{c}\text { Total } \\
n\end{array}$} & \multirow{3}{*}{$\mathrm{p}$ value } \\
\hline & & \multicolumn{2}{|c|}{ Users } & \multicolumn{2}{|c|}{ Non-users } & & \\
\hline & & $N$ & $\%$ & $N$ & $\%$ & $N$ & \\
\hline \multirow{4}{*}{ Age group } & $15-19$ & 12 & 5.9 & 24 & 6.8 & 36 & \multirow{4}{*}{0.004} \\
\hline & $25-29$ & 84 & 41.6 & 122 & 34.7 & 206 & \\
\hline & $30-34$ & 57 & 28.2 & 75 & 21.3 & 132 & \\
\hline & $35-39$ & 7 & 3.5 & 40 & 11.4 & 47 & \\
\hline Mean \pm SD (Range) & & \multicolumn{2}{|c|}{$27.4 \pm 4.6(18-38)$} & \multicolumn{2}{|c|}{$27.5 \pm 5.3(18-39)$} & & $\begin{array}{c}\mathrm{t}=0.3 ; \mathrm{df}=552 ; \\
\mathrm{p}=0.7\end{array}$ \\
\hline \multirow[t]{4}{*}{ Marital status } & Single & 12 & 5.9 & 20 & 5.7 & 32 & \multirow{4}{*}{0.1} \\
\hline & Married & 179 & 88.6 & 306 & 86.9 & 485 & \\
\hline & Divorced & 4 & 2.0 & 20 & 5.7 & 24 & \\
\hline & Widow & 7 & 3.5 & 6 & 1.7 & 13 & \\
\hline \multirow[t]{4}{*}{ Level of education } & Never been to school & 2 & 1.0 & 11 & 3.1 & 13 & \multirow{4}{*}{0.01} \\
\hline & Primary level & 104 & 51.5 & 193 & 54.8 & 297 & \\
\hline & Secondary level & 51 & 25.3 & 104 & 29.6 & 155 & \\
\hline & College/University & 45 & 22.3 & 44 & 12.5 & 89 & \\
\hline \multirow{2}{*}{ Religious affiliation } & Catholic & 51 & 27.7 & 98 & 28.9 & 149 & \multirow[t]{2}{*}{0.1} \\
\hline & Muslim & 6 & 3.3 & 25 & 7.4 & 31 & \\
\hline \multirow[t]{4}{*}{ Employment status } & Farmer & 122 & 63.5 & 252 & 74.1 & 374 & \multirow{4}{*}{0.008} \\
\hline & Self-employed & 5 & 2.6 & 17 & 5.0 & 22 & \\
\hline & Employed & 26 & 13.5 & 28 & 8.2 & 54 & \\
\hline & Other & 39 & 20.3 & 43 & 12.6 & 82 & \\
\hline \multirow[t]{3}{*}{ Employment status of husband } & Farmer & 112 & 60.2 & 197 & 62.3 & 309 & \multirow{3}{*}{$<0.0001$} \\
\hline & Self-employed & 21 & 11.3 & 76 & 24.1 & 97 & \\
\hline & Employed & 53 & 28.5 & 43 & 13.6 & 96 & \\
\hline \multirow[t]{3}{*}{ Average monthly income (KShs) } & $<10,000$ & 113 & 58.6 & 200 & 58.7 & 313 & \multirow[t]{3}{*}{$<0.0001$} \\
\hline & $10,000-29,999$ & 24 & 12.4 & 89 & 26.1 & 113 & \\
\hline & $\geq 30,000$ & 56 & 29.0 & 52 & 15.2 & 108 & \\
\hline \multirow[t]{2}{*}{ Head of household } & Self & 14 & 7.2 & 33 & 9.5 & 47 & \\
\hline & Husband & 179 & 92.7 & 313 & 90.5 & 492 & 0.4 \\
\hline Number of people living in the & None & 0 & 0.0 & 1 & 0.3 & 1 & \\
\hline household in past 6 months & 1 & 0 & 0.0 & 15 & 4.3 & 15 & \\
\hline excluding & $2-5$ & 47 & 24.7 & 64 & 18.3 & 111 & 1.0 \\
\hline income to the household in past & 1 & 96 & 48.2 & 229 & 65.8 & 325 & \\
\hline 6 months & 2 & 50 & 25.1 & 60 & 17.2 & 110 & 1.0 \\
\hline & $\geq 2$ & 3 & 1.5 & 2 & 0.6 & 5 & \\
\hline Self-perceived household & Very poor & 35 & 17.6 & 56 & 15.9 & 91 & \\
\hline economic status & Moderate & 86 & 43.2 & 159 & 45.2 & 245 & 0.8 \\
\hline & Not poor & 78 & 39.2 & 137 & 38.9 & 215 & \\
\hline
\end{tabular}

5. Bivariate analysis of the demographic and socioeconomic influencing utilization of maternal health care services

Table 2 presents findings on bivariate analysis of the demographic and socio-demographic factors influencing utilization of maternal health care services. Where respondent's occupation was farming, a significantly smaller proportion of users (32.6\%) compared with occupations $(44.4 \%)$. Forty percent of users who were farmers were less likely to utilize maternal health care services $(\mathrm{OR}=0.6 ; 95 \%$ CI: $0.4-0.9 ; \mathrm{p}=0.007)$. Similarly, households with one member of the family bringing income in the last 6 months were $50 \%$ less likely to have used the facilities than those with more than one member. Results show that $29.5 \%$ of the users with one family bringing income in this category actually utilized the facility in comparison to $46.3 \%$ of households with more than one family member bringing income to the household $(\mathrm{OR}=0.5 ; 95 \% \mathrm{CI}: 0.3-0.7 ; \mathrm{p}$ $<0.0001)$. The results suggest that farming as an occupation and having fewer dependents bringing income in the household negatively affects utilization of maternal health services in the research area. 
TABLE 2: BIVARIATE ANALYSIS OF THE DEMOGRAPHIC AND SOCIOECONOMIC DETERMINANTS OF HEALTH SERVICES UTILIZATION IN THE PAST 6 MONTHS

\begin{tabular}{|c|c|c|c|c|c|c|c|}
\hline \multirow{3}{*}{ Variables } & \multirow{3}{*}{ Categories } & \multirow{2}{*}{ Total } & \multicolumn{2}{|c|}{ Utilization } & \multirow{3}{*}{ OR } & \multirow{3}{*}{$95 \% \mathrm{CI}$} & \multirow{3}{*}{$\mathrm{p}$ value } \\
\hline & & & Users & Non-users & & & \\
\hline & & $\mathrm{N}$ & $\%$ & $\%$ & & & \\
\hline \multirow[t]{2}{*}{ Age group } & $<25$ & 169 & 32.0 & 68.0 & \multirow{2}{*}{0.7} & \multirow{2}{*}{$0.5-1.1$} & \multirow{2}{*}{0.1} \\
\hline & $\geq 25$ & 385 & 38.4 & 61.6 & & & \\
\hline \multirow{2}{*}{ Marital status } & Married & 485 & 36.9 & 63.1 & \multirow{2}{*}{1.2} & \multirow{2}{*}{$0.9-2.0$} & \multirow{2}{*}{0.6} \\
\hline & Others & 69 & 33.3 & 66.7 & & & \\
\hline \multirow[t]{2}{*}{ Level of education } & None/Primary & 310 & 34.2 & 65.8 & \multirow{2}{*}{0.8} & \multirow{2}{*}{$0.6-1.1$} & \multirow{2}{*}{0.2} \\
\hline & Secondary and above & 244 & 39.3 & 60.7 & & & \\
\hline \multirow[t]{2}{*}{ Religion } & Protestants & 343 & 37.0 & 63.0 & \multirow{2}{*}{1.1} & \multirow{2}{*}{$0.7-1.5$} & \multirow{2}{*}{0.7} \\
\hline & Others & 211 & 35.6 & 64.4 & & & \\
\hline Respondent's & Farmer & 374 & 32.6 & 67.4 & \multirow{2}{*}{0.6} & \multirow{2}{*}{$0.4-0.9$} & \multirow{2}{*}{0.007} \\
\hline Occupation & Others & 180 & 44.4 & 55.6 & & & \\
\hline Husband's & Farmer & 309 & 36.2 & 63.8 & \multirow{2}{*}{1.0} & \multirow{2}{*}{$0.7-1.4$} & \multirow{2}{*}{0.9} \\
\hline Occupation & Others & 245 & 36.7 & 63.3 & & & \\
\hline \multirow[t]{2}{*}{ Income (KShs.) } & $<10,000$ & 313 & 36.1 & 63.9 & \multirow{2}{*}{1.0} & \multirow{2}{*}{$0.7-1.4$} & \multirow{2}{*}{0.8} \\
\hline & $\geq 10,000$ & 241 & 36.9 & 63.1 & & & \\
\hline \multirow{5}{*}{$\begin{array}{l}\text { Number of people living in } \\
\text { household } \\
\text { Number of people bringing } \\
\text { income to a household } \\
\text { Economic status }\end{array}$} & $\geq 5$ & 413 & 34.6 & 65.4 & 07 & $05-11$ & 01 \\
\hline & $<5$ & 141 & 41.8 & 58.2 & 0.1 & $0.5-1.1$ & 0.1 \\
\hline & One & 325 & 29.5 & 70.5 & & & \\
\hline & More than one & 229 & 46.3 & 53.7 & 0.5 & $0.3-0.1$ & $<0.0001$ \\
\hline & Moderately poor & 245 & 35.1 & 64.9 & 0.9 & $0.6-1.3$ & 0.5 \\
\hline
\end{tabular}

6. Infrastructure factors influencing utilization of maternal health care services

Table 3 shows results on bivariate analysis of infrastructure factors influencing the utilization of maternal health services in the research area. A higher proportion of users $(41.4 \%)$ who perceived that private/mission facilities in the study area had better qualified staff utilized the services $(\mathrm{OR}=2.8 ; 95 \% \mathrm{CI}: 1.8-4.6 ; \mathrm{p}<0.0001)$ compared with their counterparts who thought otherwise. The former were almost 3 times more likely to have used the facilities if they believed that facilities in private/mission had better qualified staff. The association between the users and status of physical infrastructure of the nearest health facility $(p=0.06)$, status of surrounding environment of the nearest health facility $(\mathrm{p}=0.07)$ and status of the infrastructure of the nearest maternity of the health facilities $(p=0.08)$ yielded borderline results with $30 \%$ of the users being less likely to have utilized the maternal health care services unlike their colleagues. The general physical state of physical and human resources in government facilities in the area resulted in non-statistically significant result.

TABLE 3: BIVARIATE ANALYSIS OF THE INFRASTRUCTURE AND HEALTH SERVICES UTILIZATION

\begin{tabular}{|c|c|c|c|c|c|c|c|}
\hline \multirow{3}{*}{ Variables } & \multirow{3}{*}{ Categories } & \multirow{2}{*}{ Total } & \multicolumn{2}{|c|}{ Utilization } & \multirow{3}{*}{ OR } & \multirow{3}{*}{$95 \% \mathrm{CI}$} & \multirow{3}{*}{$\mathrm{p}$ value } \\
\hline & & & Users & Non-users & & & \\
\hline & & $n$ & $\%$ & $\%$ & & & \\
\hline \multirow{2}{*}{$\begin{array}{l}\text { Status of physical infrastructure of the } \\
\text { nearest health facility }\end{array}$} & Good & 402 & 34.1 & 65.9 & \multirow{2}{*}{0.7} & \multirow{2}{*}{$0.5-1.0$} & \multirow{2}{*}{0.06} \\
\hline & Poor & 152 & 42.8 & 57.2 & & & \\
\hline \multirow{2}{*}{$\begin{array}{l}\text { Status of surrounding environment of } \\
\text { the nearest health facility }\end{array}$} & Safe and clean & 427 & 34.4 & 65.6 & \multirow{2}{*}{0.7} & \multirow{2}{*}{$0.4-1.0$} & \multirow{2}{*}{0.07} \\
\hline & Unsafe and unclean & 127 & 43.3 & 56.7 & & & \\
\hline \multirow{2}{*}{$\begin{array}{l}\text { Status of the infrastructure of the } \\
\text { nearest maternity of the health } \\
\text { facilities in the area }\end{array}$} & Good & 439 & 34.6 & 65.4 & \multirow[b]{2}{*}{0.7} & \multirow[b]{2}{*}{$0.4-1.0$} & \multirow[b]{2}{*}{0.08} \\
\hline & Poor & 115 & 43.5 & 56.5 & & & \\
\hline \multirow{2}{*}{$\begin{array}{l}\text { The general state of physical and } \\
\text { human resources in government } \\
\text { facilities in the area }\end{array}$} & \multirow{2}{*}{$\begin{array}{l}\text { Better qualified staff } \\
\text { Others }\end{array}$} & 393 & 38.4 & 61.6 & \multirow[b]{2}{*}{1.3} & \multirow[b]{2}{*}{$0.9-2.0$} & \multirow[b]{2}{*}{0.1} \\
\hline & & 161 & 31.7 & 68.3 & & & \\
\hline The general state of physical and & Better qualified staff & 428 & 41.4 & 58.6 & & & \\
\hline $\begin{array}{l}\text { human resources in private/mission } \\
\text { facilities in the area }\end{array}$ & Others & 126 & 19.8 & 80.2 & 2.8 & $1.8-4.6$ & $<0.0001$ \\
\hline
\end{tabular}

7. Accessibility factors influencing utilization of maternal health care services

The results on the accessibility factors influencing utilization of maternal health care services are presented in Table 4. The findings show a statistically significant association between the fare for a public vehicle, the fare for Boda Boda (motorcycle taxis) and duration to the health facility and utilization of maternal health care services. Where fare for the public vehicle was KSh. 20 (USD 0.2) users were three-fold more likely to have utilized the services compared to those who paid more (OR $=3.1 ; 95 \%$ CI: 2.0 - 4.6; $\mathrm{p}<0.0001)$. The same was true where users who spent at most Ksh. 50 (USD 0.5) were upto three times more likely to utilize the services in comparison to those who spent more than this amount (USD 0.5) $(\mathrm{OR}=2.1 ; 95 \%$
CI: 1.3 - 3.3; $\mathrm{p}=0.0008)$. Cheaper transport, therefore, encourages utilization of maternal health care services in the study area. There was also a significant association between the time taken to the health facility by public vehicle and utilization of the services. A higher proportion of respondents who took less than $30 \mathrm{~min}$ by use of public vehicles compared with those who took at least $30 \mathrm{~min}$ or more utilized maternal health services $(\mathrm{OR}=3.4 ; 95 \% \mathrm{CI}$ : 1.0 - 11.6; $\mathrm{p}=0.04)$. Users taking less than $30 \mathrm{~min}$ were three times more likely to have used the services than those who spent more time on travel to reach the facility. Respondents who visited the health facility as a patient were two times more likely have utilized the services than those went as a visitor or escorted a patient $(\mathrm{OR}=1.9$; 95\% CI: 1.0 - 3.6; $\mathrm{p}=0.06)$. The difference was, however, marginally 
statistically significant. The results also show that respondents who spent at least $30 \mathrm{~min}$ or more when traveling to the health facility on foot were less likely to have used the services $(35.4 \%)$ as opposed to those who spent less than 30 min using the same mode of transport
(48.9\%), the difference being statistically borderline (OR $=0.6 ; 95 \%$ CI: $0.3-1.1 ; \mathrm{p}=0.07)$. Results imply that distance plays major role in inaccessibility to the health facilities by clients seeking maternal health services.

TABLE 4: BIVARIATE ANALYSIS OF ACCESSIBILITY FACTORS INFLUENCING UTILIZATION MATERNAL HEALTH CARE SERVICES

\begin{tabular}{|c|c|c|c|c|c|c|c|}
\hline \multirow{3}{*}{ Variables } & \multirow{3}{*}{ Categories } & \multirow{2}{*}{ Total } & \multicolumn{2}{|c|}{ Utilization } & \multirow{3}{*}{ OR } & \multirow{3}{*}{$95 \% \mathrm{CI}$} & \multirow{3}{*}{$\mathrm{p}$ value } \\
\hline & & & Users & Non-users & & & \\
\hline & & $n$ & $\%$ & $\%$ & & & \\
\hline \multirow{4}{*}{$\begin{array}{l}\text { Duration respondent has } \\
\text { lived in the study area } \\
\text { Type of nearest health } \\
\text { facility }\end{array}$} & Since birth & 262 & 38.9 & 61.1 & \multirow{2}{*}{1.2} & \multirow{2}{*}{$0.9-1.7$} & \multirow{2}{*}{0.2} \\
\hline & Less than 12 months & 292 & 34.2 & 65.8 & & & \\
\hline & Health Centre & 264 & 34.9 & 65.1 & \multirow{2}{*}{0.9} & \multirow{2}{*}{$0.6-1.2$} & \multirow{2}{*}{0.4} \\
\hline & Dispensary & 290 & 37.9 & 62.1 & & & \\
\hline \multirow[t]{2}{*}{ Ownership of health facility } & Government & 436 & 35.6 & 64.4 & \multirow{2}{*}{0.8} & \multirow{2}{*}{$0.5-1.3$} & \multirow{2}{*}{0.4} \\
\hline & NGO, Private, etc & 118 & 39.8 & 60.2 & & & \\
\hline \multirow{2}{*}{$\begin{array}{l}\text { They visited health facility in } \\
\text { what status }\end{array}$} & As a patient & 501 & 37.7 & 62.3 & \multirow[b]{2}{*}{1.9} & \multirow[b]{2}{*}{$1.0-3.6$} & \multirow[b]{2}{*}{0.06} \\
\hline & $\begin{array}{l}\text { As a visitor or escorting } \\
\text { patient }\end{array}$ & 53 & 24.5 & 75.5 & & & \\
\hline \multirow{2}{*}{$\begin{array}{l}\text { Distance from nearest health } \\
\text { facility }\end{array}$} & $<5 \mathrm{~km}$ & 541 & 36.6 & 63.4 & \multirow{2}{*}{1.3} & \multirow{2}{*}{$0.4-4.3$} & \multirow{2}{*}{0.7} \\
\hline & $\geq 5 \mathrm{~km}$ & 13 & 30.8 & 69.2 & & & \\
\hline \multirow{2}{*}{$\begin{array}{l}\text { Duration to health facility by } \\
\text { foot }\end{array}$} & $\geq 30 \mathrm{~min}$ & 509 & 35.4 & 64.4 & \multirow{2}{*}{0.6} & \multirow{2}{*}{$0.3-1.1$} & \multirow{2}{*}{0.07} \\
\hline & $<30 \mathrm{~min}$ & 45 & 48.9 & 51.1 & & & \\
\hline \multirow{2}{*}{$\begin{array}{l}\text { Duration to health facility by } \\
\text { boda boda }\end{array}$} & $<30 \mathrm{~min}$ & 539 & 36.2 & 63.8 & \multirow{2}{*}{0.6} & \multirow{2}{*}{$0.2-1.8$} & \multirow{2}{*}{0.4} \\
\hline & $\geq 30 \mathrm{~min}$ & 15 & 46.7 & 53.3 & & & \\
\hline Duration to health facility by & $<30$ min & 534 & 37.3 & 62.7 & 34 & & 004 \\
\hline public vehicle & $\geq 30 \mathrm{~min}$ & 20 & 15.0 & 85.0 & 3.4 & $1.0-11.6$ & 0.04 \\
\hline Fare for boda boda (KShs.) & $\leq 50$ & 425 & 40.2 & 59.8 & & & \\
\hline & $>50$ & 129 & 24.0 & 76.0 & 2.1 & $1.3-3.3$ & 0.0008 \\
\hline Fare for a public vehicle & 20 & 370 & 44.3 & 55.7 & & & \\
\hline (KShs.) & $>20$ & 184 & 20.6 & 79.4 & 3.1 & $2.0-4.6$ & $<0.0001$ \\
\hline
\end{tabular}

8. Quality of care factors influencing utilization of maternal health care services

Table 5 presents quality of care factors associated with utilization of maternal health care services. Rating of quality of care provided in public health facilities significantly influenced utilization of the services with a significantly smaller proportion of users who rated the care as good $(34.6 \%)$ using the services as opposed to those who thought the quality of care was poor $(50.8 \%)(\mathrm{OR}=0.5 ; 95 \% \mathrm{CI}: 0.3$ - 0.9; $\mathrm{p}=0.01)$. Similar evidence was noted where users rated the quality of health staff in public facilities as being good $(34.4 \%)$ compared to those of contrary opinion $(48.7 \%)$, the results being statistically significant $(\mathrm{OR}=0.5$; $95 \% \mathrm{CI}: 0.3-0.9 ; \mathrm{p}=0.01)$. On the contrary, where the rating of health staff in private facilities was very good a higher proportion of users $(37.4 \%)$ than those given a lower rating of good or poor utilized the services. The findings were statistically significant $(\mathrm{OR}=3.8 ; 95 \% \mathrm{CI}$ : $1.1-12.9$; $\mathrm{p}=0.02$ ). Among users who viewed staff quality in private health facilities as very good were four-fold more likely to have used the services unlike those who gave lower ratings. Views on the quality of care provided in NGO health facilities, equally elicited higher odds ratio of 5.9 of utilizing maternal health care services as opposed to those who gave a rating of 'good' or 'poor' $(\mathrm{OR}=5.9 ; 95 \% \mathrm{CI}$ : $0.7-46.2$; $\mathrm{p}=0.06$ ) though when tested, the difference was marginally significant.

TABLE 5: BIVARIATE ANALYSIS OF QUALITY OF CARE FACTORS INFLUENCING HEALTH SERVICES UTILIZATION

\begin{tabular}{|c|c|c|c|c|c|c|c|}
\hline \multirow{3}{*}{ Variables } & \multirow{3}{*}{ Categories } & \multirow{2}{*}{ Total } & \multicolumn{2}{|c|}{ Utilization } & \multirow{3}{*}{ OR } & \multirow{3}{*}{$95 \% \mathrm{CI}$} & \multirow{3}{*}{$\mathrm{p}$ value } \\
\hline & & & Users & Non-users & & & \\
\hline & & $n$ & $\%$ & $\%$ & & & \\
\hline \multirow{2}{*}{$\begin{array}{l}\text { Rating of quality of care } \\
\text { provided in public health } \\
\text { facilities }\end{array}$} & \multirow{2}{*}{$\begin{array}{l}\text { Good } \\
\text { Poor }\end{array}$} & 489 & 34.6 & 65.4 & \multirow[b]{2}{*}{0.5} & \multirow[b]{2}{*}{$0.3-0.9$} & \multirow[b]{2}{*}{0.01} \\
\hline & & 65 & 50.8 & 49.2 & & & \\
\hline \multirow{2}{*}{$\begin{array}{l}\text { Rating of quality of care } \\
\text { provided in private health } \\
\text { facilities }\end{array}$} & \multirow{2}{*}{$\begin{array}{l}\text { Very good } \\
\text { Good or poor }\end{array}$} & 505 & 35.8 & 64.2 & \multirow[b]{2}{*}{0.7} & \multirow[b]{2}{*}{$0.4-1.3$} & \multirow[b]{2}{*}{0.3} \\
\hline & & 49 & 42.9 & 57.1 & & & \\
\hline \multirow{2}{*}{$\begin{array}{l}\text { Rating of quality of care } \\
\text { provided in NGO health } \\
\text { facilities }\end{array}$} & \multirow{2}{*}{$\begin{array}{l}\text { Very good } \\
\text { Good or poor }\end{array}$} & 543 & 37.0 & 63.0 & \multirow[b]{2}{*}{5.9} & \multirow[b]{2}{*}{$0.7-46.2$} & \multirow[b]{2}{*}{0.06} \\
\hline & & 11 & 9.1 & 90.9 & & & \\
\hline \multirow{4}{*}{$\begin{array}{l}\text { Rating of quality of health } \\
\text { staff in public health facilities } \\
\text { Rating of quality of health } \\
\text { staff in private health } \\
\text { facilities }\end{array}$} & Good & 474 & 34.4 & 65.6 & \multirow{2}{*}{0.5} & \multirow{2}{*}{$0.3-0.9$} & \multirow{2}{*}{0.01} \\
\hline & Poor & 80 & 48.7 & 51.3 & & & \\
\hline & Very good & 532 & 37.4 & 62.6 & \multirow[b]{2}{*}{3.8} & \multirow[b]{2}{*}{$1.1-12.9$} & \multirow[b]{2}{*}{0.02} \\
\hline & Good or poor & 22 & 13.6 & 86.4 & & & \\
\hline
\end{tabular}

9. Antenatal, delivery and postnatal care factors influencing Health Services Utilization

Table 6 shows factors associated with antenatal, delivery, postnatal care and utilization of maternal care services.
Where nurses provided ANC services, users were two times more likely to utilize the services than where other cadres provided similar services $(\mathrm{OR}=2.3 ; 95 \% \mathrm{CI}$ : $1.3-4.1$; $\mathrm{p}=0.003)$. A significantly higher proportion of users $(41.7 \%)$ 
who confirmed that their babies are checked within 24 hours after delivery were six times more likely to use the services than those who agreed that such checkup was not done within the recommended period $(\mathrm{OR}=6.5 ; 95 \% \mathrm{CI}: 3.2-$ 13.3; $\mathrm{p}<0.0001)$. Again, those who agreed that baby checkup which is done 24 hours after delivery is performed in a health facility and not at home were 16 times more likely to utilize the services (OR $=16.0 ; 95 \%$ CI: 7.7 - 33.5; $\mathrm{p}<0.0001)$. Likewise, where such checkup was done by health nurse, users were 12 times more likely to have utilized the services contrary to settings where the checkup was done by other health staff $(\mathrm{OR}=12.0 ; 95 \% \mathrm{CI}$ : $6.7-$ $21.4 ; \mathrm{p}<0.0001)$. However, respondents who professed that they had experienced complications during the PNC period were $50 \%$ less likely to have used the services $(\mathrm{OR}=0.5$; $95 \%$ CI: $0.3-0.8 ; \mathrm{p}=0.007)$. Surprisingly, a significantly smaller proportion of users $(17.5 \%)$ who were happy with the time taken to respond to emergency utilized the services compared with those who were not happy (40.9\%) as evidenced by low odds ratio $(\mathrm{OR}=0.3 ; 95 \% \mathrm{CI}$ : $0.1-0.9$; $\mathrm{p}=0.02)$.

Those who gave the reason for having not sought PNC as not having had complication were less likely to have utilized the services with a significantly smaller proportion having met the criteria of users $(32.1 \%)$ as opposed to their counterparts who sought PNC care because they had complications $(40.1 \%)$ with the results being significant $(\mathrm{OR}=0.7 ; 95 \%$ CI: $0.5-1.0 ; \mathrm{p}=0.05)$. There was a borderline significant association between mothers who started their ANC visits in 2nd trimester $(\mathrm{OR}=0.7 ; 95 \% \mathrm{CI}$ : $0.5-1.0 ; \mathrm{p}=0.06$ ) and utilization of maternal health care services. A significantly smaller proportion of those who started their ANC services (33\%) during 2nd trimester were users as opposed to their counterparts who started later. Having attended ANC during the last pregnancy, having gone to the health centre for ANC or having made PNC visits within 6 months was not statistically associated with the utilization of maternal care services.

TABLE 6: BIVARIATE ANALYSIS OF ANTENATAL, DELIVERY AND POSTNATAL CARE FACTORS INFLUENCING HEALTH SERVICES UTILIZATION

\begin{tabular}{|c|c|c|c|c|c|c|c|}
\hline \multirow{3}{*}{ Variables } & \multirow{3}{*}{ Categories } & \multirow{3}{*}{$\begin{array}{c}\text { Total } \\
n \\
\end{array}$} & \multicolumn{2}{|c|}{ Utilization } & \multirow{3}{*}{ OR } & \multirow{3}{*}{$95 \% \mathrm{CI}$} & \multirow{3}{*}{$\mathrm{p}$ value } \\
\hline & & & Users & Non-users & & & \\
\hline & & & $\%$ & $\%$ & & & \\
\hline \multirow{5}{*}{$\begin{array}{l}\text { Attended ANC during the } \\
\text { last pregnancy } \\
\text { Went to the health center } \\
\text { for ANC } \\
\text { When started ANC }\end{array}$} & Yes & 537 & 36.3 & 63.7 & \multirow[b]{2}{*}{0.8} & \multirow[b]{2}{*}{$0.3-2.2$} & \multirow{2}{*}{0.7} \\
\hline & No & 17 & 41.2 & 58.8 & & & \\
\hline & Yes & 234 & 37.6 & 62.4 & \multirow{2}{*}{1.1} & \multirow{2}{*}{$0.8-1.5$} & \multirow{2}{*}{0.6} \\
\hline & No & 320 & 35.6 & 64.4 & & & \\
\hline & $2^{\text {nd }}$ trimester & 306 & 33.0 & 67.0 & 0.7 & $0.5-1.0$ & 0.06 \\
\hline \multirow[t]{2}{*}{ Staff who provided ANC } & Nurse & 475 & 38.9 & 61.1 & \multirow{2}{*}{2.3} & \multirow{2}{*}{$1.3-4.1$} & \multirow{2}{*}{0.003} \\
\hline & Others & 79 & 21.5 & 78.5 & & & \\
\hline Baby checked within 24 & Yes & 463 & 41.7 & 58.3 & \multirow{2}{*}{6.5} & \multirow{3}{*}{$3.2-13.3$} & \multirow{2}{*}{$<0.0001$} \\
\hline hrs after delivery & No & 91 & 9.9 & 90.1 & & & \\
\hline \multirow{2}{*}{$\begin{array}{l}\text { Place where first baby } \\
\text { checkup was done within } \\
24 \text { hrs }\end{array}$} & Health facility & 406 & 47.8 & 52.2 & \multirow[b]{2}{*}{16.0} & & \multirow[b]{2}{*}{$<0.0001$} \\
\hline & At home & 148 & 5.4 & 94.6 & & $7.7-33.5$ & \\
\hline Staff who did the baby & Nurse & 374 & 50.3 & 49.7 & 12.0 & $6.7-21.4$ & $<0.0001$ \\
\hline $\begin{array}{l}\text { complications during PNC } \\
\text { period }\end{array}$ & No & 469 & 38.8 & 61.2 & 0.5 & $0.3-0.8$ & 0.007 \\
\hline Happy with time taken to & Yes & 63 & 17.5 & 82.5 & & & \\
\hline respond to emergency & No & 22 & 40.9 & 59.1 & 0.3 & $0.1-0.9$ & 0.02 \\
\hline Number of PNC visits & $\leq 2$ & 459 & 36.0 & 64.0 & & & \\
\hline made within 6 months & $>2$ & 95 & 39.0 & 61.0 & 0.9 & $0.6-1.4$ & 0.6 \\
\hline Reason for not seeking & Had no complication & 252 & 32.1 & 67.9 & & & \\
\hline PNC & Other reasons & 302 & 40.1 & 59.9 & 0.7 & $0.5-1.0$ & 0.05 \\
\hline
\end{tabular}

10. Determinants of maternal health care services utilization

A model was fitted with all the variables that were marginally or statistically significantly associated with utilization of maternal health services in the study area. All the independent variables with a $\mathrm{p}$ value of less than or equal to 0.08 were included in the model. The outcome of the model where each independent predictor variable is tested holding the rest constant (controlling for confounders) is presented in Table 7. Eleven variables were independently associated with utilization of maternal health care services. These included mothers occupation, number of people bringing income to the household, status of infrastructure of the nearest maternity of the health facilities in the area, fare for public vehicle, maternal health services available in nearest health facility, suitability of the working days, there being some services client pays for, rating of quality of care provided in public health facilities, when started ANC visit, staff who provided ANC and staff who did the baby check-u within 24 hours, all of which were statistically significantly associated with utilization of maternal care services. One independent variable, that is time taken to health facility by public vehicle showed a borderline association with utilization of maternal health services $(p=0.07)$. Predictors that promote use of maternal health care services are: respondents being a farmer $(\mathrm{OR}=2.6 ; 95 \% \mathrm{CI}: 1.4-4.8 ; \mathrm{p}=$ 0.002 ), status of the infrastructure of the nearest maternity of the health facilities in the area being good $(\mathrm{OR}=3.2 ; 95 \%$ CI: 1.1-9.6; $\mathrm{p}=0.03$ ), fare for public vehicle being Ksh. 20 (USD 0.2) $(\mathrm{OR}=3.4 ; 95 \% \mathrm{CI}: 1.6-7.1 ; \mathrm{p}=0.001)$, all maternal health services being available in the nearest health facility $(\mathrm{OR}=3.1 ; 95 \% \mathrm{CI}: 1.8-5.4 ; \mathrm{p}<0.0001)$, difficulty to attend $\mathrm{MCH}$ services due to non-suitability of working days $(\mathrm{OR}=2.7 ; 95 \% \mathrm{CI}: 1.5-4.7 ; \mathrm{p}=0.0008)$, there being some 
services that clients pay for $(\mathrm{OR}=3.3 ; 95 \% \mathrm{CI}$ : $1.5-7.4$; $\mathrm{p}=0.004$ ), services being provided by nurses (midwives) $(\mathrm{OR}=2.3 ; 95 \% \mathrm{CI}: 1.0-4.9 ; \mathrm{p}=0.04)$ and baby check up being done within 24 hours by nurses $(\mathrm{OR}=18.8$; $95 \% \mathrm{CI}$ : 8.0-44.0; $\mathrm{p}<0.0001)$. It is also important to note that, although marginally significantly associated with utilization of MCH services, clients who take less than 30 minutes to reach the nearest health facility by public vehicle were up to 29 times more likely to use the facilities $(\mathrm{OR}=5.1 ; 95 \% \mathrm{CI}$ :
0.9-28.7; $\mathrm{p}=0.07)$.

Barriers to utilization of MHC services utilization include household economic status where one person brings income to the household (OR $=0.3 ; 95 \%$ CI: 0.2-0.6; $\mathrm{p}=0.0002$ ), rating of quality of care provided in public health facility as being $\operatorname{good}(\mathrm{OR}=0.1 ; 95 \% \mathrm{CI}$ : $0.03-0.64 ; \mathrm{p}=0.01)$ and starting $\mathrm{ANC}$ in the $2 \mathrm{nd}$ trimester $(\mathrm{OR}=0.5 ; 95 \% \mathrm{CI}$ : 0.3 $0.9 ; \mathrm{p}=0.02$ ).

TABLE VII: MULTIPLE LOGISTIC REGRESSION ON DETERMINANTS OF MATERNAL HEALTH CARE SERVICES UTILIZATION

\begin{tabular}{|c|c|c|c|c|c|}
\hline Variables & Categories & Estimate & OR & $95 \% \mathrm{CI}$ & $\mathrm{p}$ value \\
\hline $\begin{array}{l}\text { Respondent's } \\
\text { Occupation }\end{array}$ & Farmer vs Others & 0.96 & 2.6 & $1.4-4.8$ & 0.002 \\
\hline Number of people bringing income to household & One vs More than one & -1.14 & 0.3 & $0.2-0.6$ & 0.0002 \\
\hline Duration to health facility by public vehicle & $<30 \min v s \geq 30 \mathrm{~min}$ & 0.61 & 5.1 & $0.9-28.7$ & 0.07 \\
\hline Fare for public vehicle (KShs.) & $20 \mathrm{vs}>20$ & 1.21 & 3.4 & $1.6-7.1$ & 0.001 \\
\hline $\begin{array}{l}\text { Maternal health services available in nearest health } \\
\text { facility }\end{array}$ & $\begin{array}{l}\text { ANC, delivery, PNC vs Not } \\
\text { all services }\end{array}$ & 1.14 & 3.1 & $1.8-5.4$ & $<0.0001$ \\
\hline Suitability of the working days & $\begin{array}{l}\text { Difficult for me to attend vs } \\
\text { Others }\end{array}$ & 0.99 & 2.7 & $1.5-4.7$ & 0.0008 \\
\hline There are some services client pays for & Yes vs No & 1.19 & 3.3 & $1.5-7.4$ & 0.004 \\
\hline $\begin{array}{l}\text { Rating of quality of care provided in public health } \\
\text { facilities }\end{array}$ & Good vs Poor & -1.94 & 0.1 & $0.03-0.64$ & 0.01 \\
\hline When started ANC & $\begin{array}{l}2^{\text {nd }} \text { trimester vs Other } \\
\text { trimesters }\end{array}$ & -0.74 & 0.5 & $0.3-0.9$ & 0.02 \\
\hline Staff who provided ANC & Nurse vs Others & 0.81 & 2.3 & $1.0-4.9$ & 0.04 \\
\hline
\end{tabular}

\section{B. Discussion}

The proportion of ANC clients was higher in the postpolicy period $(54.1 \% ; 55825 / 103,251)$ compared to the prepolicy period $(45.9 \% ; 47426 / 103,251)$. These results agree with KDHS report [10] which noted an increase in antenatal attendance up to $96 \%$ up from $92 \%$ reported in the KDHS [16]. This is supported by the MOH [17] comprehensive report which also noted that there was increased utilization of ANC services in the year of initiating free maternity care. The results are attributed to the removal of user fees which has been one of the barriers to utilizing maternity services. These results are similar to those reported by Ameyaw [18] and Mahamadu [19] in Ghana. The authors noted an increase in antenatal attendance in post-policy periods. However, contrary results were observed in Cambodia where utilization increased following fee introduction. It was attributed to perceived improved quality of care according to [3].

Differentials in delivery care by background characteristics of the mother are generally similar to those for antenatal care. Higher numbers were observed in the post-free maternity $(55.7 \%$; $(9666 / 17338)$ compared to the pre-free maternity period of $44.5 \%$ (7722/17338). The increase in the number of mothers utilizing maternal health services is linked to the removal of financial barriers. The results of this study are supported by the Comprehensive Assessment Report which was carried out in Kenya to assess the status of implementation of free maternity services programs in the devolved health. The findings from the assessment revealed that with the introduction of fees facility deliveries increased and decreased following the removal of fees. The reason given was that removing the fee compromised the quality of maternal health services hence discouraging mothers from utilizing the services.
While data for the pre-policy period for post-natal checkup was missing for the period 2010 to 2014, results on postfree maternity period after this period showed progressive increasing trend in postnatal attendance from $11.3 \%$ $(598 / 5291)$ in 2015 to $42.4 \%(2244 / 5291)$ in 2017 , respectively. The increase could be attributed to increased number of women coming to deliver in the health facilities following implementation of free maternity care which increases the likehood of improved postnatal check-up visits. Literature review reveals that most of the studies measuring the impact of user fee removal on the utilization of maternal services have not reported much on postnatal services probably because of the unavailability of data. Similar results were observed by Mahamadu [19] who noted that postnatal attendance was progressing slowly and needed a boost.

Multivariate logistic regression analysis revealed that eleven key independent variables determine the utilization of maternal health care in the study area. However, one independent variable, that is the time taken to reach the health facility by public vehicle showed a borderline association with utilization of maternal health care. The respondent being a farmer, the infrastructure of the nearest maternity of the health facilities in the area being good, fare for the public vehicle being twenty shillings, availability of maternal health services, non-suitability of working days, payment of some services by the client, services being provided by nurses, baby checkup being done within 24 hours by nurses and clients who take less than 30 minutes to reach the nearest health facility by the public vehicle were statistically significantly associated with maternal health care utilization and therefore identified as the key determinants of maternal health care utilization.

Farmers were three times likely to have used the facilities 
compared to other occupations. Being a farmer in a rural setting is connected to low economic status and therefore makes farmers utilize free maternity services more. These findings are consistent with findings from a study that was carried out in south-eastern Nigeria on causes of patterns of maternal and child health service application in a rural community where there was consistently high rates of utilization of maternal health services among farmers. Farmers are, on many occasions, less socio-economically vested and as such will prefer health amenities providing care at minimal cost if not free [20]-[22]. These findings are similar to results reported by Ayele et al. [23] on factors affecting utilization of maternal health care services in Kombolcha District, Eastern Ethiopia where women farmers were more likely to use maternal health care services compared to housewives though the reason for utilization is different. The explanation given is that farming as an occupation is related to the economic power which translates to the ability to access the services if it costs are involved.

Respondents who paid fare of less than USD 0.2 using public service vehicle were three times more likely to have used the services than those who paid more. Amount of fare paid depends on distance covered. This means that mothers could access the services because they were closer to them. According to [24], some of the barriers to maternal health care utilization were that the health facility was far and that they lacked means of transport among other factors. The study findings are comparable with what Anyait et al. [25] found out in Busia Uganda, a rural district in Eastern Uganda, where among the predictors on utilization of maternal health care services was having no difficulty with paying transport to access health facilities.

Women who paid for some services in the health facilities were three times more likely to have used the services. Services that mothers pay for include buying Jik, gloves, cotton wool, syringes, and needles yet according to FMC policy, these services are supposed to be free in Kenya. The cost of these items ranges from USD $0.3-0.5$. Mothers buy these commodities/supplies when the government delays in releasing funds meant for free maternity services to health facilities. The findings of this study could be attributed to the positive relationship between user fees and other factors such as staff attitude towards clients, accessibility, affordability, availability, and acceptability of the services. More importantly, it shows that mothers are likely to visit a health facility in search of satisfactory health services. The study results concur with research carried out in Nigeria where it was shown that patients were willing to accept costs that were higher when they thought that the services were of superior quality. The research findings further revealed that good provider-client relationship can be therapeutic and could be the most important factor of health care that not only helps in identifying problems quickly and clearly but also helps create trust between provider and client [26]. Nonetheless, Kimani, Mugo \& Kioko [27] had contrary findings. Their results indicated that user fees hurt health care service utilization. The same sentiments were expressed by Gakii [28] who indicated that if user fees were to rise, the probability of seeking care at private and mission clinics would increase. Likewise, a research carried out in
Malaysia revealed that women who did not have to spend at the healthcare facility were 1.9 times more likely to use maternal health care services [29].

The odds of utilizing the services provided by nurses (midwives) were two times higher when compared with other cadres. This is perhaps because nurse-midwives are the main service providers for maternal health care services. They spend more time with patients than other cadres like clinical officers and doctors who are tasked with other responsibilities and not necessarily providing direct care to mothers during ANC, delivery or post-natal care. Nurses are the primary staff in many health care systems and whatever care they provide is recognized by clients as essential.

Respondents whose babies were examined by nurses within 24 hours after delivery were 19 times more likely to have used the services. This could be attributed to the fact that checking the baby after delivery is important to ensure that the baby is free from complications and is doing well. Mothers prefer being attended to by skilled birth attendants to avoid complications that may arise during or following delivery. Checking the baby is a component of good quality service. When a woman receives good quality service it results in increased client satisfaction, which consequently ensures continued uptake of services [30].

It is also important to note that, although marginally significantly related to utilization of maternal health care services, clients who take less than 30 minutes to get to the nearest health facility by the public vehicle were up to 29 times more likely to have utilized the amenities. This may be associated with the fact that the services are affordable in terms of the cost of accessing them. The outcomes are consistent with results from the systematic review of the literature on Factors influencing the utilization of maternal health services in resource strained countries, where many studies identified the cost of accessing care (travel cost, service fees, equipment cost) as a barrier to utilization of maternal health care services. Results of this study also agree with findings of Anyait et al. [25] in Busia Uganda, where among the predictors of utilization of maternal health care services was having no difficulty with transport which suggests staying in close proximity to a health facility.

\section{CONCLUSION}

The number of mothers utilizing maternal health care services has increased in this era of free maternity services. Free maternity health care services are a good strategy for improving on utilization of maternal health care service by mothers. The free maternal services, however, are facing some challenges. There are inadequate personnel particularly nurses, inadequate infrastructure, insufficient commodities in health facilities, delay by the national government to release money meant for FMC services to health facilities. These challenges should be dealt with by the heads of health facilities with support from policymakers. The high utilization rate without logical evidence of better investments to improve quality of care (more infrastructure, staff, commodities) implies provision of sub-standard service to mothers.

The study established eleven predictors of MHC service utilization in the era of free maternity program in Busia County. These were: respondents being a farmer, status of 
the infrastructure of the nearest maternity of the health facilities in the area being good, fare for the public vehicle being Ksh. 20 (USD 0.2), all maternal health services being available in the nearest health facility, difficulty to attend ANC services due to non-suitability of working days, there being some services that clients pay for, services being provided by nurses (midwives) and baby checkup being done within 24 hours by nurses, clients who take less than 30 minutes to reach the nearest health facility by public vehicle among others.

Barriers related to utilization of maternal health care services included unreliable transport especially at night, limited infrastructure, and low socio-economic status of the women in the study area.

\section{RECOMMENDATIONS}

Governments intending to remove user fees must, therefore, plan strategically and link this single action to broader improvements within the health system especially the infrastructure and human resources to take care of the high utilization rate of the services by women. National and County governments need to put in place strategies which will help them to jointly assess, map and plan investments to improve utilization of FMC through prioritizing investments in human resource, infrastructure, and commodities based on the anticipated demand for FMC. The National and County Governments should establish clear monitoring and evaluation procedures to track the results of the program and also establish a tracking system to ensure that FMC refunds are committed to improving maternal health services as advised. This monitoring system should cover utilization trends and give health workers and managers the opportunity to give feedback on health facility experience. The National Government should improve on the efficiency of claims processing and payment, minimize the payment delays, and frequently review the amount allocated to deliveries to meet the growing cost of items. The FMC programme should be extended to the private sector and faith-based health facilities to broaden the impact of this intervention particularly in reducing congestion in the public health facilities particularly in the use of maternal health services. Linda Mama programme and the National Health Insurance Fund (NHIF) should allow mothers to choose a health facility of their choice regardless of whether private or public.

\section{ACKNOWLEDGEMENT}

Special thanks go to my supervisors: Dr. Mary Kipmerewo and Mr. John Arudo School of Nursing, Midwifery, and Paramedical Sciences (SONMAPS) of Masinde Muliro University of Science and Technology, Kenya for their treasured input and efforts in the design of the study and review of the manuscript. Much gratitude to Prof. John Okoth of SONMAPS for providing invaluable guidance on literature review. I also wish to thank my employer, Ministry of Health, Busia County for offering me study leave which enabled me to accomplish this work.

Lastly, I would like to acknowledge my family who provided both financial and moral support without which I would not have realized my study goals.

\section{REFERENCES}

[1] WHO, UNICEF, UNFPA, and The World Bank, Trends in maternal mortality: 1990 to 2015 WHO, Geneva, 2015.

[2] Tey, N. (2013). Correlates of and barriers to the utilization of health services for delivery in South Asia and Sub-Saharan Africa. The Scientific World Journal 2013(1): 423403.

[3] Dzakpasu, S., Powell-Jackson, T., \& Campbell O.M. (2013). Impact of user fees on policy maternal health service utilization and related health outcomes: A systematic review. Health and Planning; 1-14. Doi:10.1093/heapol/CSS 142.

[4] Dzakpasu, S., Soremekun, S., Manu, A., ten Asbroek, G., Tawiah, C., Hurt, L., \& Kirkwood, B. R. (2012). Impact of free delivery care on health facility delivery and insurance coverage in Ghana's Brong Ahafo region. PLOS ONE 7(11): e49430. doi: 10.1371/journal.pone.0049430.

[5] Kenya National Bureau of Statistics (KNBS) and ICF Macro. (2014). Kenya Demographic and Health Survey.

[6] KSPA 2010; Kenya service provision assessment SURVEY (2010).

[7] Ministry of Health (MOH) 2013: Report on Maternal Health care in Kenya.

[8] Bourbonnais, N. (2013). Implementing Free Maternity Care in Kenya, Challenges, strategies, and recommendation - KNCHR

[9] Save the Children USA 501 King's Highway East, Suite 400Fairfield, CT 06825 1-800-728-3843.

[10] KDHS, 2014; Kenya National Bureau of Statistics (KNBS) and ICF Macro. (2014). Kenya Demographic and Health Survey, Kenya Vision 2030

[11] Kenya National Bureau of Statistics [KNBS], Ministry of Health/Kenya, National AIDS Control Council/Kenya, Kenya Medical Research Institute, National Council for Population and Development/Kenya, and ICF International. 2015.

[12] Government of Kenya (2012-2017). Kenya health sector strategic plan, Busia county government (2013-2017). County integrated development planChidiebere et al., (2009).

[13] Atasige, S. A. (2014). Factors Influencing the Uptake of Intermittent Preventive Treatment of Malaria among Pregnant Women in the Gushegu District,Northern Region, Ghana (Doctoral dissertation, University of Ghana).

[14] Ameh, S., Owoaje, E., Oyo-Ita, A. et al. Barriers to and determinants of the use of intermittent preventive treatment of malaria in pregnancy in Cross River State, Nigeria: a cross-sectional study. BMC Pregnancy Childbirth 16, 99 (2016). https://doi.org/10.1186/s12884016-0883-2.

[15] Fisher A.A., Laing J. E., Stoeckel J.E and Townsend J.W (1991). Handbook for Family Planning Operations Research Design 2nded. p43.Population Council. New York, USA Available on: www.popcouncil.org.

[16] Kenya National Bureau of Statistics (KNBS) and ICF Macro. (2010). Kenya Demographic and Health Survey 2008-09.

[17] Ministry of Health, Health Sector Monitoring \& Evaluation Unit, (2015). Status of the program in the devolved health system in Kenya. A Comprehensive Assessment Report. WHO and UKAID.

[18] Ameyaw, E. A. (2011). An Assessment of the Effect of the Free Maternal Care Policy on the Utilisation of Maternal Care Services in the New Juaben Municipality (Doctoral dissertation, Institute of Distance Learning, Kwame Nkrumah University of Science and Technology, Kumasi).

[19] Mahamadu, A. H. (2012). Access and utilization of free maternal health service in the Savelugu-Nanton district in the Northern region. (Doctoral Dissertation University of Cape Town).

[20] Ochako, R., FotsoJ-C, IkamariL., and Khasakhala A., (2011). Emergency Obstetric Care Services' Utilization. Journal of Urban Health, 88(Suppl 2): 356-369.

[21] Abosse Z, Woldie M, Ololo S. Factors influencing antenatal care service utilization in hadiya zone. Ethiop J Health Sci. 2010; 20(2):75-82. doi:10.4314/ejhs.v20i2.69432.

[22] Birmeta, K., Dibaba, Y. \& Woldeyohannes, D. Determinants of maternal health care utilization in Holeta town, central Ethiopia. BMC Health Serv Res 13, 256 (2013). https://doi.org/10.1186/1472-6963 13-256.

[23] Ayele, D. Z., Belayihun, B., Teji, K., \& Ayana, D. A. (2014). Factors Affecting Utilization of Maternal Health Care Services in Kombolcha District , Eastern Hararghe Zone , Oromia Regional State , Eastern Ethiopia. International Scholarly Research Notices, 2014(2001), 7.

[24] Lerberg, P. M., Sundby, J., Jammeh, A., \& Fretheim, A. (2014). Barriers to skilled birth attendance: a survey among mothers in rural Gambia. African journal of reproductive health, 18(1), 35-43. 
[25] Anyait A, Mukanga D, Oundo GB, \&Nuwaha F. (2012) Predictors for health facility delivery in Busia district of Uganda: a cross-sectional study. BMC Pregnancy Childbirth.; 12.

[26] Nwaeze IL, Enabor OO, Oluwasola TA, Aimakhu CO. Perception and satisfaction with quality of antenatal care services among pregnant women at the university college hospital, ibadan, Nigeria. Ann Ib Postgrad Med. 2013; 11(1):22-28.

[27] Kimani, D., Mugo, M. \& Kioko, U. (2016) An Econometric Analysis Of Health Care Utilization in Kenya. European Scientific Journal. 12(16):10-19.

[28] Gakii, J. (2013). Demand for Health Care in Kenya: The Effect of Health Insurance. Nairobi: Kenya Institute for Public Policy Research and Analysis.

[29] Rahman MM, Ngadan DP, Arif MT. Factors affecting satisfaction on antenatal care services in Sarawak, Malaysia: evidence from a cross sectional study. Springerplus. 2016;5(1):725. Published 2016 Jun 16 doi:10.1186/s40064-016-2447-3.

[30] Anne M Molloy, Kristina Pentieva, Breige McNulty, Helene McNulty, Reply to SW D'Souza et al, The American Journal of Clinical Nutrition, Volume 98, Issue 6, December 2013, Pages 15981599, https://doi.org/10.3945/ajen.113.073593. 